\title{
Fibrosis index predicts variceal bleeding and reduces need for nonselective beta-blocker in compensated cirrhosis with initial small esophageal varices without red-color sign
}

\author{
Sheng-Fu Wang ${ }^{1}$, Yu-Tung Huang ${ }^{2}$, Chien-Hao Huang ${ }^{1,2,3,4}$, Shang-Hung Chang ${ }^{2,3,4}$, Chun-Yen Lin ${ }^{1,3}$ \\ ${ }^{1}$ Division of Hepatology, Department of Gastroenterology and Hepatology, Chang-Gung Memorial Hospital, Linkou Medical Center, Taoyuan; \\ ${ }^{2}$ Center for Big Data Analytics and Statistics, Department of Medical Research and Development, Chang Gung Memorial Hospital, Linkou Medical \\ Center, Taoyuan; ${ }^{3}$ School of Medicine, College of Medicine, Chang-Gung University, Taoyuan; ${ }^{4}$ Cardiovascular Division, Department of Internal \\ Medicine, Chang Gung Memorial Hospital, Linkou Medical Center, Taoyuan \\ Contributions: (I) Conception and design: CH Huang; (II) Administrative support: CY Lin; (III) Provision of study materials or patients: SH Chang; \\ (IV) Collection and assembly of data: SF Wang, CH Huang; (V) Data analysis and interpretation: YT Huang; (VI) Manuscript writing: All authors; \\ (VII) Final approval of manuscript: All authors. \\ Correspondence to: Chien-Hao Huang, MD, PhD. 5, Fu-Xin Street, Quain San, 330, Taoyuan. Email: huangchianhou@gmail.com.
}

\begin{abstract}
Background: Various non-invasive markers predicting hepatic fibrosis are poor predictors of esophageal variceal bleeding (EVB). Elastography performs well but resource-limited. Controversy for small EV prevention also exists. We aim to investigate if a non-invasive marker could predict subsequent EVB within 1 and 2 years in patients with compensated liver cirrhosis (CLC), initial small EV without red-color sign (RCS), without use of non-selective beta-blockers (NSBB) and endoscopic variceal ligation (EVL). This marker would also be tested if it could help reduce use of NSBB, thereby avoiding potential side effects and saving medical costs.
\end{abstract}

Methods: In this retrospective cohort study, 6,803 CLC patients fulfilling the inclusion-exclusion criteria were enrolled between 2001 and 2018, and were followed-up for 1 year, 2 years. The primary outcomes were subsequent EVB within 1 and 2 years of enrollment. Another 281 CLC patients with NSBB use were compared for additional outcome analysis.

Results: In total, 539 patients and 710 patients experienced EVB within 1 year and 2 years, respectively. The fibrosis index (FI) with cut-off value of 3.95 showed a negative predictive value (NPV) of $94.3 \%$ and an area under receiver operating characteristic (AUROC) of $62.95 \%$ for predicting subsequent EVB within 1 year. The EVB and mortality of patients with FI $<3.95$ and not taking NSBB were significantly lower than those of the other 3 groups. Similar results were demonstrated within 2 years.

Conclusions: In CLC patients with initial small EV and no RCS, low FI scores showed a high NPV and moderate AUROC in predicting subsequent EVB and mortalities, signifying clinically non-significant portal hypertension. Patients with low FI scores and not taking NSBB had significantly lowest EVB and mortality. The medical cost savings for cutting NSBB in these patients would be estimated at least $\$ 3$ million per year in the U.S. Further randomized control trial study needed to validate this screening tool.

Keywords: Fibrosis index (FI); non-selective beta-blockers (NSBB); small esophageal varices; esophageal variceal bleeding (EVB); compensated liver cirrhosis (CLC); endoscopic variceal ligation (EVL); medical cost savings

Submitted Mar 12, 2020. Accepted for publication Aug 07, 2020.

doi: $10.21037 / \mathrm{atm}-20-2444$

View this article at: http://dx.doi.org/10.21037/atm-20-2444 


\section{Introduction}

Esophageal variceal bleeding (EVB) is a common but life-threatening complication in patients with liver cirrhosis regardless of cirrhosis etiology, resulting in high morbidity and mortality despite the improvement in the efficacy of endoscopic, pharmacologic, surgical, and radiologic techniques (1). In addition, the reported 1-year mortality for variceal bleeding ranges from $14.1 \%$ to $57 \%$ (2-4). Therefore, selecting high-risk patients to undergo preventative measures is crucial. On the other hand, distinguishing those low-risk patients for less aggressive care may also help reduce medical expenditure and avoid side effects.

The main factors leading to the development of varices are continued hepatic injury, degree of portosystemic shunting, endoscopic appearances and portal pressure (5). Among these, the presence of large varices has demonstrated a major risk factor for the emergence of variceal hemorrhage $(6,7)$. In patients with approximate portal hypertension, the likelihood of acute variceal bleeding is significantly increased in patients with large varices (6).

Furthermore, certain endoscopic variceal stigma collectively referred to as "red-color sign" (red-whale markings, cherry-red spots, nipple symptoms, hematocystic spots), were correlated with a significantly higher risk of acute variceal bleeding $(7,8)$. In addition, patients with advanced liver disease [Child-Turcotte-Pugh C (CTP-C), presence of ascites or hepatic encephalopathy] are also more likely to experience EV bleeding $(6,9)$. Hence, it is strongly recommended that either non-selective betablocker (NSBB) usage or esophageal variceal ligation (EVL) be performed to prevent primary variceal bleeding among medium or large varices (10).

However, previous studies show debatable results for primary prevention of small esophageal varices by NSBB, especially for those with no endoscopic red-color sign (RCS) or with compensated liver cirrhosis (CLC) (11-13). UK guidelines recommend NSBBs as primary prophylaxis in grade I varices only when red-signs are present, and also recommended annual EGD monitoring (5). Baveno V/VI and AASLD guidelines recommend that NSBBs should be used for primary prophylaxis in patients with small varices who are judged to be at increased risk of bleeding, i.e. those that show red color/wale sign upon initial endoscopy or who are graded as CTP-C $(9,10)$. Consequently, for these compensated cirrhotic patients with small varices and lack of red color/wale sign, further studies were suggested in Baveno VI and AASLD guideline to confirm the benefit of $\operatorname{NSBB}(9,10)$.

Moreover, a group of cirrhotic patient with small varices indicate clinically significant portal hypertension (CSPH) but may have uneven risk of bleeding with different hepatic venous pressure gradient (HVPG) (14). Nevertheless, HVPG is an invasive procedure and one study showed that HVPG monitoring did not change outcome in cirrhotic patients with small EV (13). Moreover, the costeffectiveness of HVPG measurement has been challenged in the primary prevention of EV bleeding $(15,16)$. Therefore it is less frequently practiced in Taiwan.

Recently, various non-invasive markers such as model for end-stage liver disease (MELD), aspartate aminotransferase (AST) to alanine aminotransferase (ALT) ratio (AST/ALT), AST to platelet ratio index (APRI), platelet count to spleen diameter (PC/SD), fibrosis-4-index (FIB-4), fibrosis index (FI) and King's score, have been demonstrated as simple, non-invasive, and easier practical alternatives to predict the presence of $\mathrm{EV}$ in cirrhotic patients (17). Additionally, the combination of albumin-bilirubin grade and platelets (PALBI) to predict EVB in compensated patients with hepatocellular carcinoma has also been described (18). However, the predictive abilities of these non-invasive markers for predicting EVB are poor with area under receiver operating characteristic (AUROC) between 0.45 and 0.55 (17).

Therefore, we aim to identify an acceptable non-invasive screening tool for distinguishing between high or lowrisk EVB group in CLC population with initial small EV, no RCS, and no history of beta-blocker prophylaxis and prophylactic EVL unless EVB or EV progression in a one and two-year follow-up. Since primary prevention may be needed for the high-risk group and spared for the lowrisk group, this marker would also be tested if it could help reduce the use of NSBB in low-risk group.

We present the following article in accordance with the STROBE reporting checklist (available at http://dx.doi. org/10.21037/atm-20-2444).

\section{Methods}

\section{Study design and data source}

This was a retrospective cohort study conducted at the Chang Gung Memorial Hospital (CGMH) system, which is the largest hospital system composing two medical centers, 


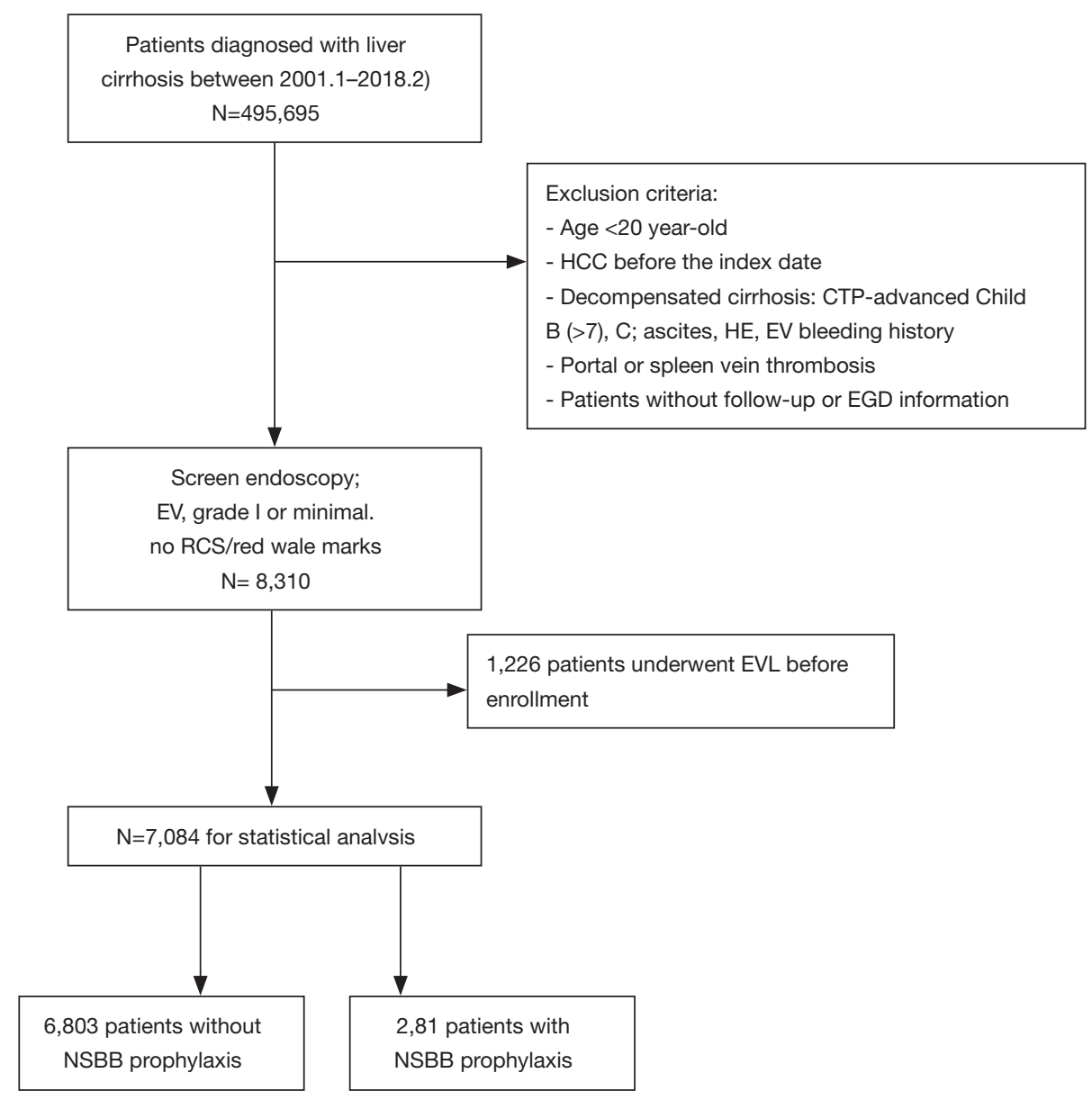

Figure 1 Enrollment flowchart. After inclusion and exclusion, 8,310 compensated liver cirrhotic patients with low-risk EV enrolled in our study from January 2001 to February 2018. After excluding patients who had undergone prophylactic therapy with EVL, the remaining 6,803 patients without NSBB prophylaxis were the main group for primary endpoint analysis. The minor group was 281 matched patients (3.97\%) with NSBB prophylaxis for secondary endpoint analysis. EV, esophageal variceal; EVL, endoscopic variceal ligation; NSBB, non-selective beta-blockers.

two regional hospitals, and three district hospitals located from the northeast to southern regions of Taiwan (19). Data were obtained from the Chang Gung Research Database (CGRD), an electronic medical records based research database maintained by the CGMH system. The CGRD includes not only outpatient, emergency, and inpatient claim records, but also contains laboratory, endoscopic, microbiological, and image, etc. reports. The more detail information about CGRD had reported in the previous article (20). The study was conducted in accordance with the Declaration of Helsinki (as revised in 2013). The study was reviewed and approved by the Institutional Review Board (IRB)/ethical committees of Chang Gung Memorial Hospital (IRB number: 201802006B0). Individual consent for this retrospective analysis was waived.

\section{Patient selection}

As depicted in the enrollment flowchart (Figure 1), the inclusion criteria were all consecutive patients diagnosed with liver cirrhosis between January 2001 and February 2018. It also requires these patients to receive screen endoscopy and diagnosed as EV, grade 1 or minimal, and no RCS or no red wale marks. The exclusion criteria were as follows: age $<20$ years old, HCC before enrollment, advanced CTP-B (>7) \& CTP-C (21), cirrhosis-related complications (ascites, HE, EV bleeding history), thrombosis of portal or spleen vein, and patients without 
follow-up information. Patients with previous endoscopic variceal ligation $(\mathrm{EVL})(\mathrm{n}=1,226)$ were also excluded in the study.

All endoscopies were performed at our institutions by experienced gastroenterologists using Olympus GIF240/260 gastrointestinal videoscopes. The grading of varices was evaluated using the system proposed by the Japanese Research Society for Portal Hypertension (22). Text mining using the SAS regular expression technique was performed for searching keywords "minimal EV/esophageal varices, Form $1 \mathrm{EV}$, grade $1 \mathrm{EV}$ ", "red-color sign/RCS/red wale marks/cherry red spot/hematocystic spot" (23), "esophageal variceal ligation/EVL", and their synonyms in the endoscopic reports. Two independent gastroenterologists had further confirmed their validity.

As a result, cirrhotic patients $\geq 20$ years old with lowrisk $\mathrm{EV}$ (small or grade 1 or form $1 \mathrm{EV}$, and no RCS, $\mathrm{n}=7,084)$ documented in CGRD were enrolled for statistic analysis. The main group was 6,803 patients without NSBB prophylaxis and without EVL for primary endpoint analysis. The minor group was 281 matched patients with NSBB prophylaxis for secondary endpoint analysis.

\section{Diagnosis criteria}

The diagnosis of liver cirrhosis was confirmed by International Classification of Diseases, Ninth Revision, Clinical Modification (ICD-9-CM) diagnosis code: (571, $571.2,571.5,571.6,572.3$ ) or 10th Revision (ICD-10CM) code: K70.3, K71.7, K74.3, K74.5, K74.6, K76.6 and abdominal echography report. The diagnosis of ascites was based on diagnosis code: 789.5 (ICD-9) or R18, K70.31, K71.51 (ICD-10). The diagnosis of hepatic encephalopathy was based on diagnosis code: 348.3, 572.2 (ICD-9); G93.4 (ICD-10). The diagnosis of EV bleeding was based on diagnosis code: 456.20, 530.82, 456.0 (ICD-9); I85.11, I85.01 (ICD-10).

The diagnosis of low-risk EV (small EV or grade $1 /$ form $1 \mathrm{EV}$, no RCS) was confirmed by screening upper endoscopic reports for the earliest findings of the above keywords. Text mining using the SAS regular expression technique was performed for searching keywords in the endoscopic reports, and we further confirmed validity by two independent gastroenterologists.

\section{Non-invasive markers for comparison of predicting $E V B$}

The following non-invasive markers were calculated for each patient: CTP score, MELD score, MELD-Na score, Platelet-albumin-bilirubin (PALBI) score, gamma-glutamyl transpeptidase-to-platelet ratio (GPR), gamma-glutamyl transpeptidase-to-albumin ratio (GAR), AST/ALT, APRI, $\mathrm{PC} / \mathrm{SD}$, spleen diameter, portal vein size, fibrosis-4-index (FIB-4), FI, King's score, Log score, Lok index, and Forns index. In addition, spleen diameter and portal vein size were considered based on abdominal echography reports.

The formulas for these non-invasive markers were listed in Table S1.

\section{The primary, secondary endpoint and follow-up time}

The primary endpoint is defined as EV bleeding during 1 and 2 years' follow-up period respectively. The secondary endpoint is defined as overall mortality during 1 and 2 years' follow-up period, respectively.

Follow-up time was defined as an interval starting from a patient was enrolled until their primary or secondary endpoint event happened or until the last medical record during the study period.

\section{Statistical analysis}

For descriptive statistics, continuous variables are expressed as mean (standard deviation) or median (IQR), and categorical variables are expressed as frequencies and percentages. The independent $t$-test was used to compare continuous variables between patients with $\mathrm{EV}$ bleeding and non-EV bleeding, while the $\chi^{2}$ test was used to compare categorical variables. Fisher's exact test was performed when more than $20 \%$ of data points presented an expected frequency of $<5$. Univariable and/or multivariable Cox regression analyses were used to assess the hazard ratio of various clinical factors and scores for predicting EV bleeding within 1 and 2 years, respectively.

After significant variables emerged, AUROC curve analysis was used to assess their balance cut-off value and accuracy in predicting EV bleeding within one and two years. Hanley and McNeil test (24) was used to conduct an inter-measure comparison. Post-hoc tests for pairwise comparison included the Bonferroni correction to adjust the significance level. Youden's index was calculated to determine an optimal cut-off value. The sensitivity and negative predictive values (NPV) measure the proportion of actual positives and true negative results that describe the performance of an EV bleeding predictor.

A P value of $<0.05$ was considered statistically significant. 
All statistical analyses were conducted in SAS version 9.4 (SAS Institute, Cary, North Carolina).

\section{Results}

There were 8,310 compensated liver cirrhotic patients with low-risk EV (small or grade 1 or form $1 \mathrm{EV}$, and no RCS) enrolled in our study from January 2001 to February 2018 in the beginning. After excluding patients who had undergone prophylactic therapy with EVL $(n=1,226$, $14.7 \%$ ), the remaining 6,803 patients without NSBB prophylaxis were the main group for primary endpoint analysis. The minor group was 281 matched patients (3.97\%) with NSBB prophylaxis for secondary endpoint analysis (Figure 1).

\section{Baseline demographics}

First, we studied the main group (no NSBB). Their demographic characteristics, biochemical data, and noninvasive fibrotic scores are shown in Table 1. Male patients are more common $(71 \%)$. HBV infection accounts for $45.29 \%$ of all known etiologies of liver cirrhosis. During follow up, 539 patients (7.92\%) and 710 patients (10.44\%) experienced EVB within 1 year and 2 years, respectively. The result also showed that there were 266 patients (3.91\%) and 433 patients $(6.36 \%)$ who experienced variceal size progression from grade 1 to either grade 2 or grade 3 by endoscopy within 1 year and 2 years, respectively (Table 1). Overall mortality was also similar: 230 patients $(3.38 \%)$ and $313(4.6 \%)$ patients died within 1 year and 2 years, respectively (Table 1). Anti-viral agent use among those with $\mathrm{HBV}$ or HCV-related cirrhosis were at rates of $40.5 \%$ and $20.6 \%$, respectively.

Several factors were statistically different between EV bleeding and non-EV bleeding groups within 1 year and 2 years, as is demonstrated in Table 2 and Table $S 2$ respectively. The EV bleeding group was younger, contained more male, more alcoholics, more severe various fibrosis scores, and larger portal vein size (Table 2 and Table S2).

\section{Prediction of EVB within 1 year and 2 years by Cox regression analyses}

Furthermore, univariable and multivariable Cox regression analyses were performed to find significant non-invasive markers that predict EVB within 1 year (Table 3) and 2 years (Table S3). After the stepwise Cox regression analysis, nonsignificant factors like age, gender or etiology were excluded based on stepwise model selection. Therefore, there were only GPR and FI retained in our final multivariate model. The results showed that FI (1 year: HR: 1.484 , 95\% CI: 1.21-1.83, $\mathrm{P}<0.001$; 2 years: HR: 1.373 , 95\% CI: $1.156-$ 1.63, $\mathrm{P}<0.001)$ and GPR ( 1 year: HR: $1.05,95 \%$ CI: $1.03-$ $1.07, \mathrm{P}<0.001$; 2 years: HR: $1.039,95 \%$ CI: $1.018-1.060$, $\mathrm{P}<0.001$ ) could independently predict $\mathrm{EVB}$ within 1 year and 2 years significantly.

\section{FI had higher accuracy than GPR in predicting EVB by ROC analysis}

In addition, ROC analysis was conducted to assess the accuracy of these two non-invasive markers in predicting EVB within 1 and 2 years, followed by the Hanley and $\mathrm{McNeil}$ test (24) to conduct an inter-measure comparison. Results showed no significant difference, but the FI had higher accuracy in predicting EVB within 1 year (Figure 2A) and 2 years (Figure 2B). Youden's index was calculated to determine an optimal cut-off value for FI since its higher predictive value. It was revealed that a cut-off value of 3.95 of FI for predicting 1-year EVB possesses a sensitivity of $51.2 \%$, NPV of $94.3 \%$ and an AUROC of $62.95 \%$. A cut-off value of 3.31 possesses a sensitivity of $71.5 \%$, NPV of $93.3 \%$ and an AUROC of $62.25 \%$ for predicting 2-year EVB. A more detailed sensitivity, specificity, and positive and NPV for FI in predicting EVB are shown in Table S4.

\section{FI has high NPV in predicting over mortalities in addition to predicting $E V B$}

It is worth noting that FI also has high NPV in predicting over mortalities in these patients: the 1-year mortality rate for those with FI $<3.95$ was $2.98 \%$ (NPV $=97.02 \%$ ) while those with FI $\geq 3.95$ was $5.37 \%$. The 2 -year mortality rate for those with $\mathrm{FI}<3.31$ was $3.98 \%$ (NPV $=96.02 \%$ ) while those with FI $\geq 3.31$ was $6.13 \%$. A more detailed sensitivity, specificity, and positive and NPV for FI in predicting mortalities are shown in Table S5. Moreover, the 1-year and 2-year mortality rate for those with FI score less than the cut-off value and without EV bleeding was even less $(2.75 \%$ and $3.65 \%$ 
Table 1 Demographic characteristics of 6,803 patients with compensated cirrhosis and EV, F1 without NSBB or prophylactic EVL as the main group. The minor group (taking NSBB) for secondary endpoint comparison analysis is also shown

\begin{tabular}{|c|c|c|}
\hline Parameter & No NSBB (main group) $n=6,803$ & NSBB (minor group) $n=281$ \\
\hline Age (years, mean \pm SD) & $58.99 \pm 12.56$ & $55.05 \pm 13.42$ \\
\hline \multicolumn{3}{|l|}{ Etiology, n (\%) } \\
\hline HBV & $3,081(45.29)$ & $123(43.77)$ \\
\hline Alcohol & $650(9.55)$ & $65(23.13)$ \\
\hline Others $^{\$}$ & $1,739(25.56)$ & $39(13.88)$ \\
\hline \multicolumn{3}{|l|}{ Follow-up duration (months, mean $\pm \mathrm{SD}$ ) } \\
\hline To mortality & $11.68 \pm 1.71$ & $10.51 \pm 3.31$ \\
\hline \multicolumn{3}{|l|}{ Outcome, n (\%) } \\
\hline Esophageal variceal bleeding in 2 years & $710(10.44)$ & $243(86.48)$ \\
\hline Variceal size progression in 1 year & $266(3.91)$ & $84(29.89)$ \\
\hline Variceal size progression in 2 years & $433(6.36)$ & $89(31.67)$ \\
\hline Mortality in 1 year & $230(3.38)$ & $54(19.22)$ \\
\hline Mortality in 2 years & $313(4.60)$ & $58(20.64)$ \\
\hline \multicolumn{3}{|l|}{ Baseline laboratory value [median, IQR] } \\
\hline AST (U/L) & 57 [37-98] & $71[47-112]$ \\
\hline $\operatorname{ALT}(\mathrm{U} / \mathrm{L})$ & 40 [26-69] & 36 [24-59] \\
\hline PT-INR & $1.20[1.10-1.39]$ & $1.30[1.17-1.50]$ \\
\hline $\mathrm{Hb}(\mathrm{g} / \mathrm{dL})$ & $11.50[9.50-13.50]$ & $9.70[8.00-11.70]$ \\
\hline WBC $(\times 1,000 / \mu \mathrm{L})$ & $5.60[4.10-7.80]$ & $6.60[4.60-9.60]$ \\
\hline Platelet $(\times 1,000 / \mu \mathrm{L})$ & 104 [70-153] & $106.0[67.00-154.0]$ \\
\hline r-GT & $73[34-164]$ & $146.0[47.00-363.0]$ \\
\hline Cholesterol & $159[133-186]$ & $150.0[122.0-181.0]$ \\
\hline \multicolumn{3}{|l|}{ Prognostic systems [median, IQR] or $\mathrm{n}(\%)$} \\
\hline CTP score & $6[5-7]$ & $7[6-8]$ \\
\hline MELD score & $11.34[8.59-15.84]$ & $13.43[10.19-18.59]$ \\
\hline MELD-Na score & $12.00[9.00-18.00]$ & $14[11-20]$ \\
\hline
\end{tabular}

Table 1 (continued) 
Table 1 (continued)

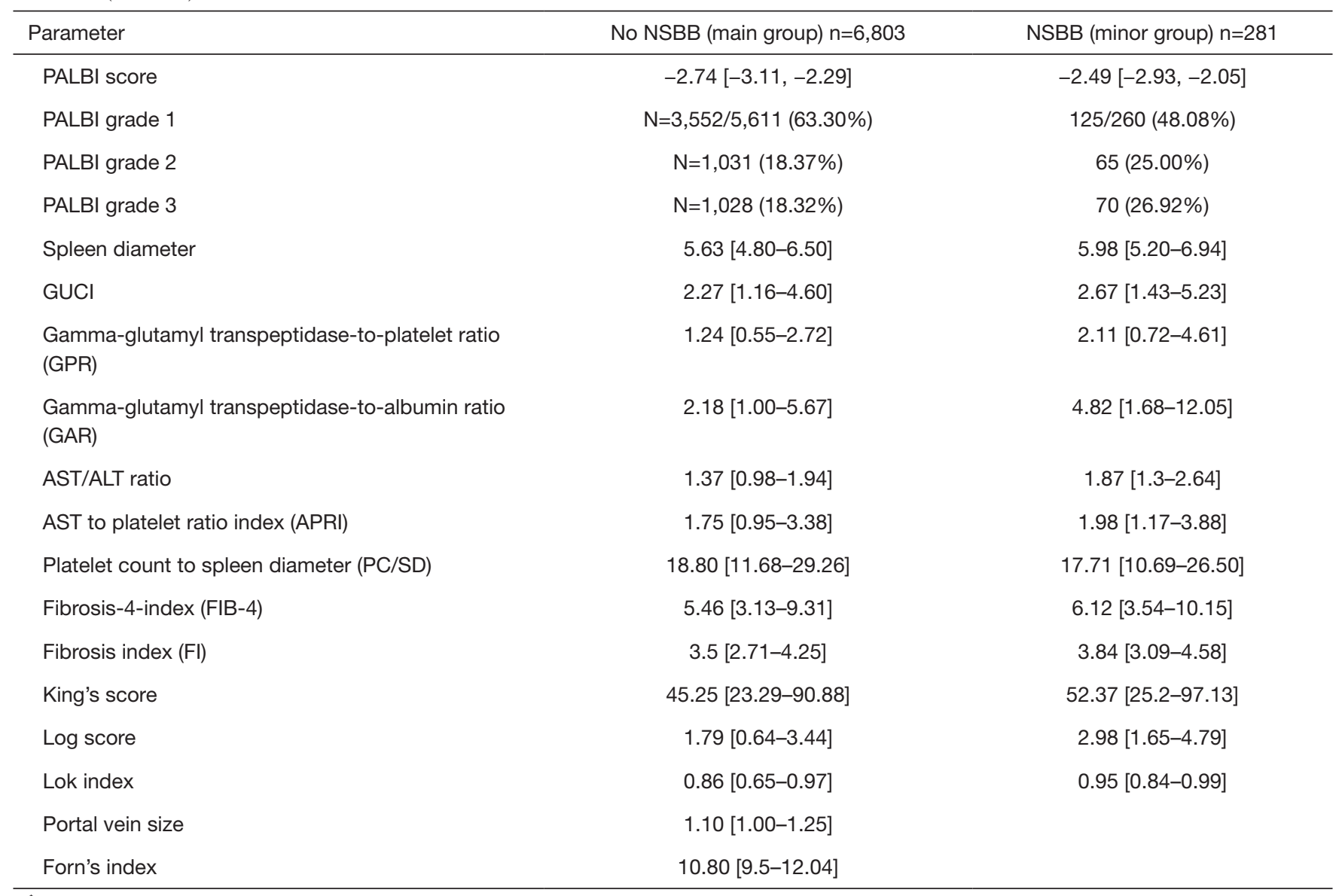

\$, non-A, non-B, non-C; EV, esophageal varices; F1, form 1 EV; NSBB, non-selective beta-blocker; EVL, esophageal band ligation; HBV, hepatitis $\mathrm{B}$ virus; $\mathrm{HCV}$, hepatitis $\mathrm{C}$ virus; $\mathrm{Hb}$, hemoglobulin.

respectively), implying those with low FI and no EVB had the best survival outcomes.

\section{Comparing between the matched non-NSBB group and the NSBB group for EV bleeding analysis}

Hence, we selected 183 patients with matched sex, age and FI score from the major and the minor group respectively for EV bleeding analysis. As shown in Table 4, the sex, age, CTP, MELD, FI scores, total bilirubin, albumin, platelet count, creatinine, INR, PALBI, APRI, Log score, King's score and Fib-4 index were matched between the nonNSBB $(n=183)$ and the NSBB group $(n=183)$. But the limitation is that the $\mathrm{Hb}, \mathrm{WBC}, \mathrm{r}-\mathrm{GT}$, GPR, GAR, and AST/ALT ratio did not match. The HR in EVB for patients not taking NSBB was significantly lower than that in patients taking NSBB $(\mathrm{HR}=0.054, \mathrm{P}<0.001$, Table 5).

\section{Comparing among four groups divided by NSBB and FI for EV bleeding and mortality analysis}

To strengthen our assumption, we further divided our entire major group who did not take NSBB and the entire minor groups who took NSBB during follow-ups before primary endpoint into four subgroups by the FI cut-off values. As shown in Figure 3, the incidence of EVB and mortality were significantly the lowest in the group 4 patients (FI lower than the cut-off values and not taking NSBB). The Kaplan-Meier curve in Figure 4A,B further suggested that patients with low FI and non-NSBB use 
Table 2 Statistical differences between EV bleeding and non-EV bleeding groups within 1 year

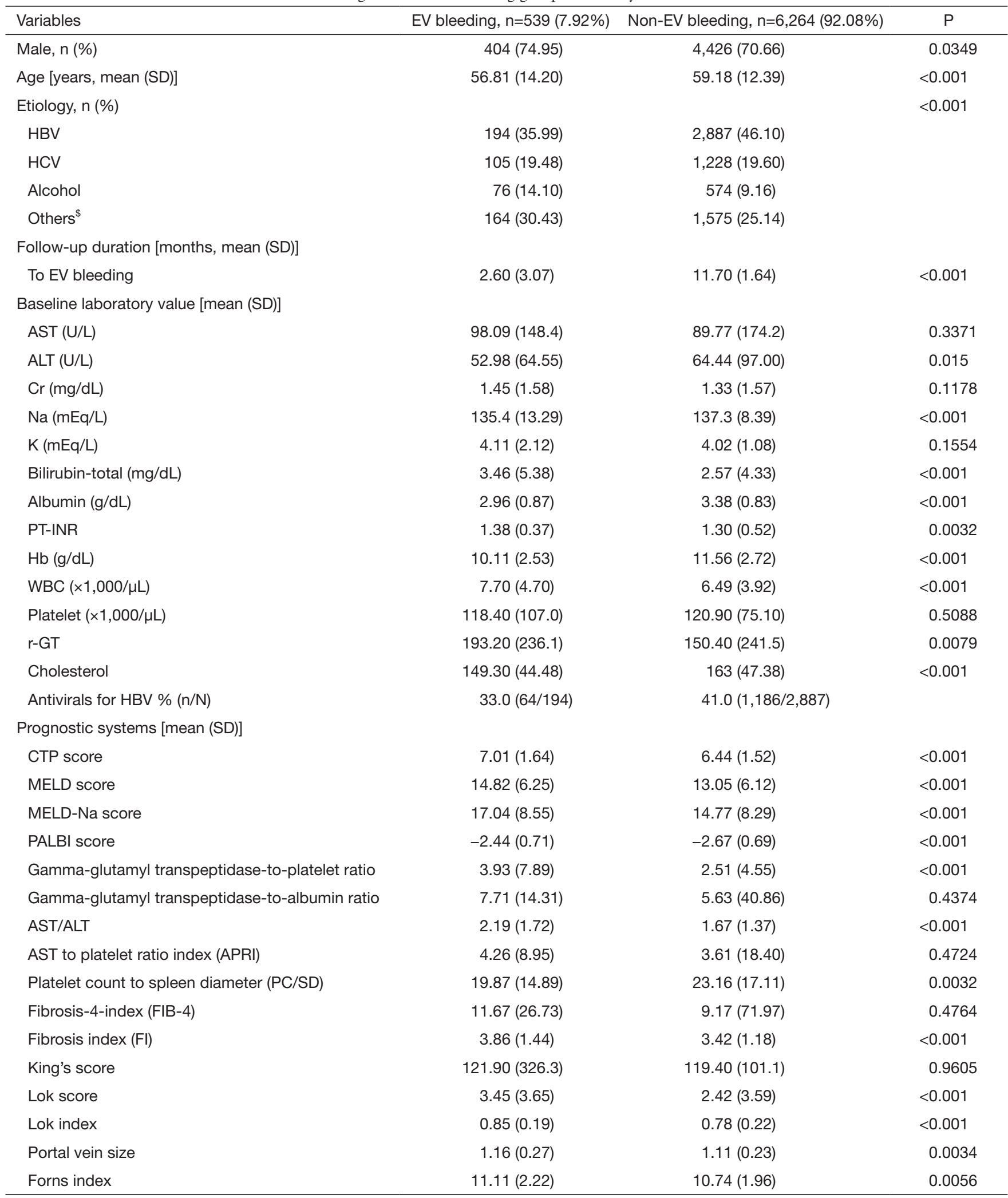

\footnotetext{
\$, non-A, non-B, non-C. EV, esophageal varices; HBV, hepatitis B virus; HCV, hepatitis C virus; Hb, hemoglobulin.
} 
Table 3 Univariable and multivariable Cox regression analysis for prediction of EV bleeding within 1 year

\begin{tabular}{|c|c|c|c|c|c|c|}
\hline Variables & \multicolumn{3}{|c|}{ Univariate } & \multicolumn{3}{|c|}{ Multivariate (stepwise) } \\
\hline Age & 0.99 & $0.98-0.99$ & $<0.01$ & & & \\
\hline \multicolumn{7}{|l|}{ Sex } \\
\hline Male & 1.00 & & & & & \\
\hline \multicolumn{7}{|l|}{ Etiology } \\
\hline HBV & 0.66 & $0.52-0.84$ & $<0.01$ & & & \\
\hline $\mathrm{HCV}$ & 0.83 & $0.65-1.06$ & 0.14 & & & \\
\hline Alcohol & 1.26 & $0.96-1.66$ & 0.09 & & & \\
\hline CTP score & 1.24 & $1.16-1.31$ & $<0.01$ & & & \\
\hline MELD score & 1.04 & $1.02-1.05$ & $<0.01$ & & & \\
\hline MELD-Na score & 1.03 & $1.01-1.03$ & $<0.01$ & & & \\
\hline PALBI score & 1.55 & $1.36-1.75$ & $<0.01$ & & & \\
\hline Spleen diameter & 1.13 & $1.03-1.22$ & 0.01 & & & \\
\hline GUCI & 1.00 & $0.99-1.00$ & 0.47 & & & \\
\hline $\begin{array}{l}\text { Gamma-glutamyl transpeptidase-to- } \\
\text { platelet ratio (GPR) }\end{array}$ & 1.03 & $1.01-1.04$ & $<0.01$ & 1.05 & $1.03-1.07$ & $<0.001$ \\
\hline Fibrosis-4-index (FIB-4) & 1.00 & $1.00-1.01$ & 0.01 & & & \\
\hline Fibrosis index (FI) & 1.38 & $1.26-1.50$ & $<0.01$ & 1.48 & $1.21-1.83$ & $<0.001$ \\
\hline King's score & 1.00 & $1.00-1.00$ & 0.59 & & & \\
\hline Lok score & 1.04 & $1.02-1.05$ & $<0.01$ & & & \\
\hline Lok index & 6.92 & $3.89-12.28$ & $<0.01$ & & & \\
\hline Portal vein size & 2.42 & $1.35-4.33$ & $<0.01$ & & & \\
\hline Forns index & 1.10 & $1.03-1.16$ & $<0.01$ & & & \\
\hline
\end{tabular}

The C-index for prediction of 1-year EV bleeding in this multivariable logistic regression model was 0.63 with $95 \% \mathrm{Cl}(0.59-0.67)$. The $\mathrm{FI}$ with a cut-off value of 3.95 showed a negative predictive value (NPV) of $94.3 \%$ for predicting subsequent EV bleeding and NPV of $97.02 \%$ for predicting mortalities within 1 year. $\mathrm{CCl}$, Charlson Comorbidity Index. 

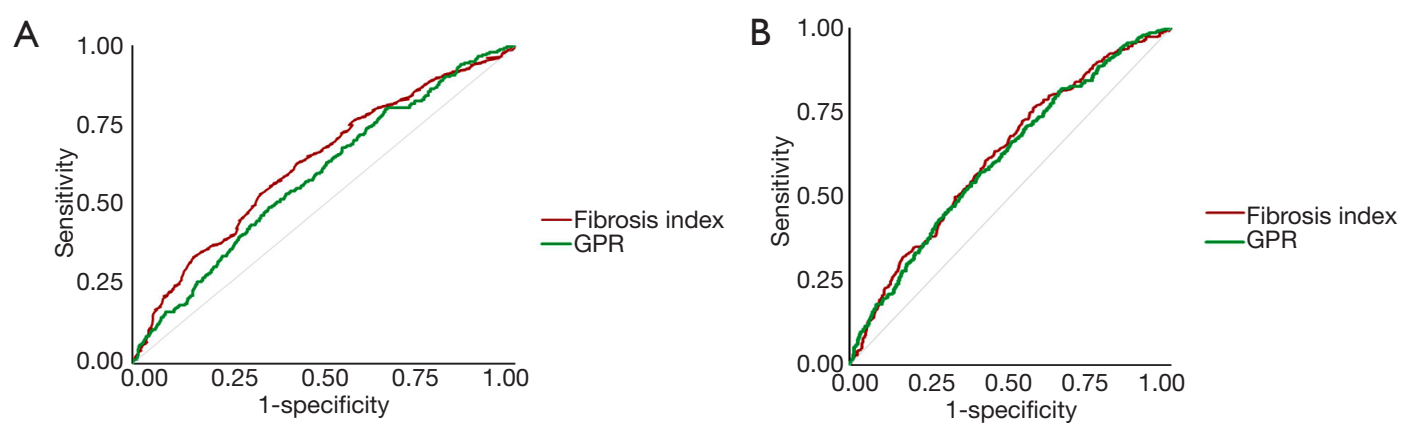

Figure 2 The fibrosis index had higher accuracy in predicting EV bleeding. (A) The fibrosis index had higher accuracy in predicting EV bleeding within 1 year than GPR had; (B) the fibrosis index had mild higher accuracy in predicting EV bleeding within 2 year than GPR had. EV, esophageal variceal; GPR, gamma-glutamyl transpeptidase-to-platelet ratio.

Table 4 Selected patients with matched sex, age and FI score from the major and the minor group respectively for EV bleeding analysis

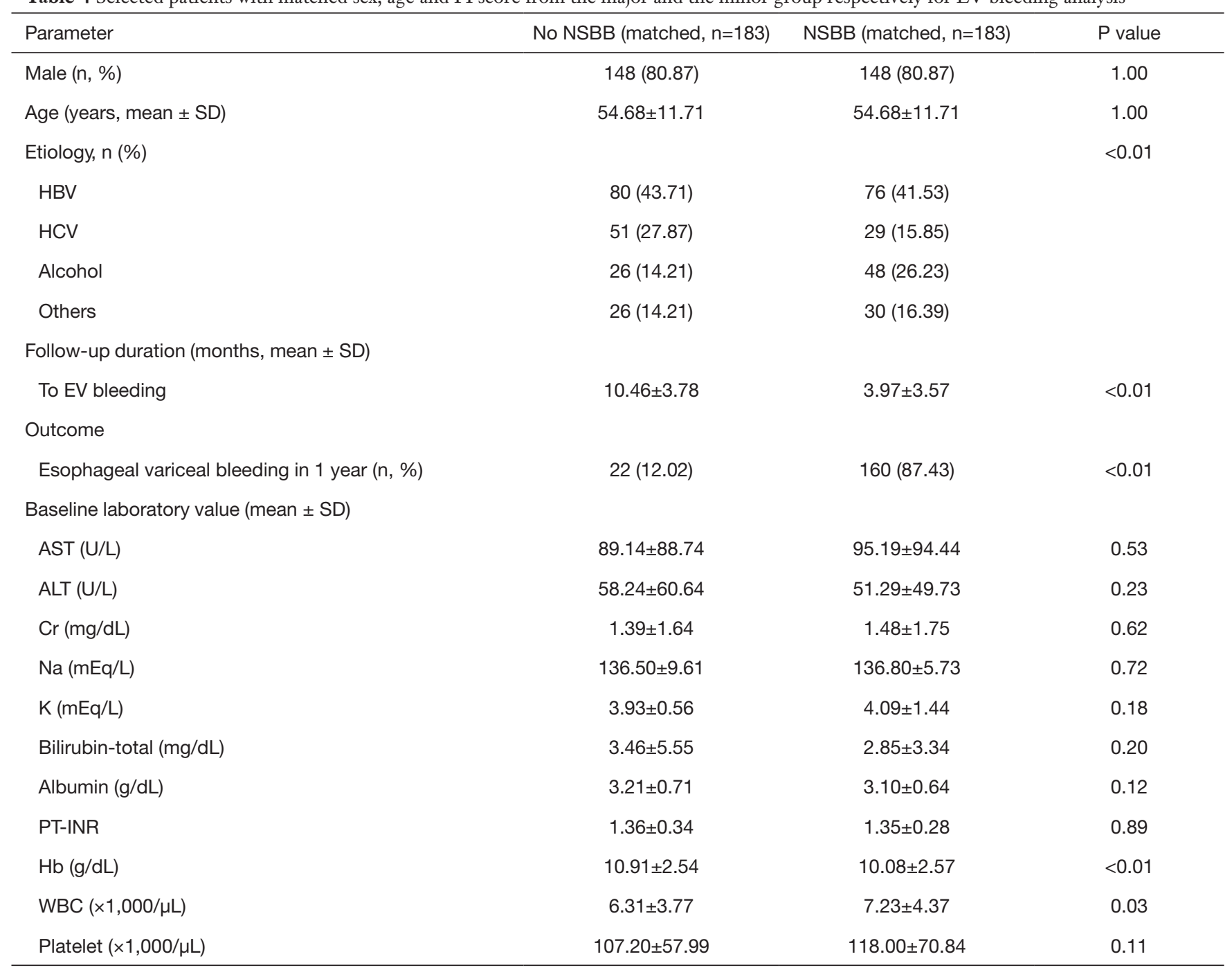

Table 4 (continued) 
Table 4 (continued)

\begin{tabular}{|c|c|c|c|}
\hline Parameter & No NSBB (matched, $n=183$ ) & NSBB (matched, $\mathrm{n}=183$ ) & $P$ value \\
\hline Cholesterol & $151.40 \pm 48.76$ & $161.00 \pm 49.88$ & 0.17 \\
\hline \multicolumn{4}{|l|}{ Prognostic systems (mean \pm SD) } \\
\hline CTP score & $6.80 \pm 1.67$ & $6.89 \pm 1.37$ & 0.61 \\
\hline MELD-Na score & $16.49 \pm 8.80$ & $15.54 \pm 6.41$ & 0.27 \\
\hline PALBI score & $-2.54 \pm 0.73$ & $-2.51 \pm 0.69$ & 0.74 \\
\hline PALBI grade 1 (n, \%) & $100(54.64)$ & $92(50.27)$ & 0.41 \\
\hline PALBI grade 2 (n, \%) & $39(21.31)$ & $50(27.32)$ & \\
\hline GUCI & $4.90 \pm 7.98$ & $4.54 \pm 5.94$ & 0.64 \\
\hline Gamma-glutamyl transpeptidase-to-platelet ratio (GPR) & $2.68 \pm 3.62$ & $3.88 \pm 5.26$ & 0.04 \\
\hline Gamma-glutamyl transpeptidase-to-albumin ratio (GAR) & $5.41 \pm 8.17$ & $9.00 \pm 11.47$ & $<0.01$ \\
\hline AST/ALT ratio & $1.87 \pm 1.43$ & $2.36 \pm 2.23$ & 0.01 \\
\hline AST to platelet ratio index (APRI) & $3.27 \pm 3.81$ & $3.26 \pm 4.03$ & 0.98 \\
\hline Platelet count to spleen diameter (PC/SD) & $18.78 \pm 10.70$ & $20.29 \pm 13.39$ & 0.37 \\
\hline Fibrosis-4-index (FIB-4) & $7.75 \pm 6.52$ & $8.53 \pm 8.91$ & 0.34 \\
\hline Fibrosis index $(\mathrm{FI})$ & $3.72 \pm 0.95$ & $3.72 \pm 0.95$ & 0.99 \\
\hline
\end{tabular}

NSBB, non-selective beta-blockers; EV, esophageal variceal; AST, aspartate aminotransferase; ALT, alanine aminotransferase.

Table 5 Hazard ratio for EVB between the patients in Table 4 in the no NSBB and the NSBB group respectively

\begin{tabular}{lccc}
\hline Variable & Hazard ratio & $95 \%$ confidence interval & P value \\
\hline No NSBB & 0.054 & $0.034-0.087$ & $<0.001$ \\
NSBB & 1.000 & & \\
\hline
\end{tabular}

NSBB, non-selective beta-blockers. 
Group 1: Fibrosis score $\geq 3.95$ ( 1 year) or $\geq 3.31$ ( 2 years) and took NSBB

Group 2: Fibrosis score $\geq 3.95$ (1 year) or $\geq 3.31$ (2 years) and did not taking NSBB

Group 3: Fibrosis score $<3.95$ (1 year) or $<3.31$ (2 years) and took NSBB

Group 4: Fibrosis score $<3.95$ (1 year) or $<3.31$ (2 years) and did not taking NSBB

A. EVB within 1 year

\begin{tabular}{|c|c|c|c|c|c|c|c|}
\hline \multirow{2}{*}{ EVB } & \multicolumn{4}{|c|}{ Group \# n (\%) } & \multirow{2}{*}{$\begin{array}{l}P \text { value } \\
P<0.001\end{array}$} & $\frac{\text { Group } 1 \text { vs. } 2}{1 \text { vs. } 3}$ & $\frac{P^{\$}<0.001}{0.2452}$ \\
\hline & 1 & 2 & 3 & 4 & & 1 vs. 4 & $<0.001$ \\
\hline \multirow[t]{2}{*}{$0^{\#}$} & \multirow[t]{2}{*}{$23(18.85)$} & \multirow[t]{2}{*}{$1758(89.01)$} & \multirow[t]{2}{*}{$19(13.57)$} & \multirow[t]{2}{*}{3451 (94.34) } & & $2 v s .3$ & $<0.001$ \\
\hline & & & & & & 2 vs. 4 & $<0.001$ \\
\hline
\end{tabular}

EVB $0^{\#}$, no EV bleeding; EVB 1, EV bleeding. $\mathrm{P}^{\$}, \mathrm{P}$ value.

B. EVB within 2 years

\begin{tabular}{|c|c|c|c|c|c|c|c|}
\hline & \multicolumn{4}{|c|}{ Group \# n (\%) } & $P$ value & Group 1 vs. 2 & $\mathrm{P}^{\$}<0.001$ \\
\hline EVB & 1 & 2 & 3 & 4 & $<0.001$ & 1 vs. 4 & $<0.001$ \\
\hline \multirow[t]{2}{*}{$0^{\#}$} & \multirow[t]{2}{*}{$28(15.38)$} & \multirow[t]{2}{*}{$2785(87.11)$} & \multirow[t]{2}{*}{$10(12.50)$} & \multirow[t]{2}{*}{$2272(93.27)$} & & 2 vs. 3 & $<0.001$ \\
\hline & & & & & & 2 vs. 4 & $<0.001$ \\
\hline
\end{tabular}

EVB $0^{\#}$, no EV bleeding; EVB 1, EV bleeding. $\mathrm{P}^{\$}, \mathrm{P}$ value.

C. Mortality within 1 year

\begin{tabular}{|c|c|c|c|c|c|c|c|}
\hline \multirow{3}{*}{ Death } & \multicolumn{4}{|c|}{ Group \# n (\%) } & \multirow{3}{*}{$\begin{array}{l}\text { P value } \\
<0.001\end{array}$} & \multirow{2}{*}{$\begin{array}{c}\text { Group } 1 \text { vs. } 2 \\
1 \text { vs. } 3\end{array}$} & \multirow{2}{*}{$\begin{array}{c}\mathrm{P}^{\$}<0.001 \\
0.049\end{array}$} \\
\hline & \multirow[t]{2}{*}{1} & \multirow[t]{2}{*}{2} & \multirow[t]{2}{*}{3} & \multirow[t]{2}{*}{4} & & & \\
\hline & & & & & & 1 vs. 4 & $<0.001$ \\
\hline \multirow[t]{2}{*}{$0^{\#}$} & \multirow[t]{2}{*}{91 (74.59) } & \multirow[t]{2}{*}{1,869 (94.63) } & \multirow[t]{2}{*}{$118(84.29)$} & \multirow[t]{2}{*}{3,549 (97.02) } & & 2 vs. 3 & $<0.001$ \\
\hline & & & & & & 2 vs. 4 & $<0.001$ \\
\hline
\end{tabular}

Death $0^{\#}$, no death. Death 1 , death (mortality). $\mathrm{P}^{\$}, \mathrm{P}$ value.

D. Mortality within 2 year

\begin{tabular}{|c|c|c|c|c|c|c|c|}
\hline \multirow{2}{*}{ Death } & \multicolumn{4}{|c|}{ Group \# n (\%) } & \multirow{2}{*}{$\begin{array}{l}P \text { value } \\
<0.001\end{array}$} & $\frac{\text { Group } 1 \text { vs. } 2}{1 \text { vs. } 3}$ & $\begin{array}{c}\mathrm{P}^{\$}<0.001 \\
0.895\end{array}$ \\
\hline & 1 & 2 & 3 & 4 & & 1 vs. 4 & $<0.001$ \\
\hline \multirow[t]{2}{*}{$0^{\#}$} & \multirow[t]{2}{*}{$142(78.02)$} & \multirow[t]{2}{*}{3,001 (93.87) } & \multirow[t]{2}{*}{$63(78.75)$} & \multirow[t]{2}{*}{ 2,339 (96.02) } & & 2 vs. 3 & $<0.001$ \\
\hline & & & & & & 2 vs. 4 & $<0.001$ \\
\hline
\end{tabular}

Death $0^{\#}$, no death. Death 1 , death (mortality). $P^{\$}, P$ value.

Figure 3 The differences in EVB and mortality rates among four groups of patients within 1 and 2 years, respectively. 

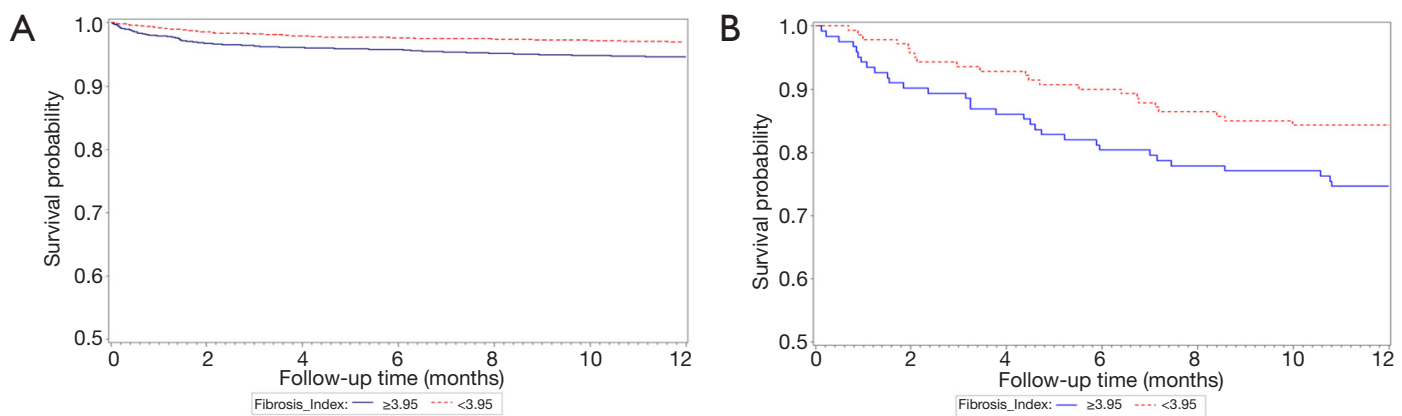

Figure 4 The Kaplan-Meier curve of four subgroups divided by the FI cut-off values (A) the entire major group who did not take NSBB and (B) the entire minor groups who took NSBB during follow-ups before the primary endpoint. FI, fibrosis index; NSBB, non-selective betablockers.

had the best survival outcome.

\section{Discussion}

In this study, we firstly demonstrated that the FI is an acceptable non-invasive marker for distinguishing higher or lower-risk EV bleeding group within 1 year or 2 years in patients with compensated cirrhosis and initial small varices without RCS and not taking beta-blockers and band ligation prophylaxis by its high NPV and moderate AUROC in predicting subsequent EVB. Based on our study, minimal bleeding risk is indicated when FI score is $<3.95$ or $<3.31$ for 1 year or 2 years given its high NPV, signifying clinically non-significant portal hypertension. In addition, the 1-year and 2-year mortality rates for patients with FI score less than these cut-off values were also found to be low (high NPV) and even lower in patients without EV bleeding. Therefore, we selected 183 patients with matched sex, age and FI score from the major and the minor group respectively for EV bleeding analysis. It revealed that patients not taking NSBB had lower EV bleeding risks. To strengthen our assumption, we further divided our entire major group who did not take NSBB and the entire minor groups who took NSBB during follow-ups before primary endpoint into four subgroups by the FI cut-off values. The result showed that the incidence of EVB and mortality were significantly the lowest in patients with FI lower than the cut-off values and not taking NSBB. The KaplanMeier curve also supported that the best survival outcome for CCC patients with initial small EV and without RCS were patients with low FI values and non-NSBB use. In other words, NSBB use was not related to death and could be avoided in this low-risk group without CSPH. Further
RCT study needed to verify the benefits of cutting NSBB in those with low FI and taking NSBB in those with high FI scores.

The management for small/low-risk EV, especially in compensated cirrhotic patients, had conflicting results $(25,26)$. Because NSBB showed adverse effects such as bradycardia, increased airway resistance, and low arterial blood pressure due to systemic vasodilation, many patients, especially those with cirrhosis, could not tolerate these drugs (27). In addition, a prior study also showed that NSBB may cause worse survival for cirrhotic patients if mean arterial blood pressure decreases to $<65 \mathrm{mmHg}$ (28). Another study found NSBB use was associated with increased risk of hepatic encephalopathy, which carries high mortality risk (29). Despite of a recent study that demonstrated the benefit of NSBB in preventing decompensation (mainly reduce ascites incidence) and improving decompensation-free survival in compensated cirrhotic patients with $\mathrm{CSPH}$ and initial none or small $\mathrm{EV}$, the incidence of high-risk $\mathrm{EV}$ formation and death from all causes were not different between NSBB and placebo groups (30). These findings suggest that NSBB may be not beneficial for all compensated cirrhotic patients with initial small EV in terms of preventing EV bleeding. That is to say, we may benefit low-risk groups by cutting back on unnecessary medication, thereby preventing complications. On the other hand, the accuracy of FI is not strong enough to predict EV bleeding within 1 or 2 years with its low PPV, hence we cannot conclude whether these FI high-risk patients would benefit from the intervention.

There is explicit indication for prevention for cirrhotic patients with high-risk EV, including large size $\mathrm{EV}$, red color sign, and Child type C patients, yet there is dispute in prophylaxis for patients with small EV due to lack of 
evidence $(5,6,9)$. While a randomized controlled trial (RCT) by Merkel et al. (12) demonstrated that conventional NSBB (nadolol) therapy is effective in preventing the progression from small to large varices in patients without prior bleeding, another RCT using propranolol by Sarin and colleagues (13) stated that NSBB prophylaxis was unable to prevent the growth of varices, EVB or mortality for small EV. The reason for the conflicting data shown in these studies could be that only some patients with small EV had reduced their HVPG sufficiently when using NSBB to demonstrate promising results. In this study, we not only found FI is the only valuable tool in predicting subsequent $\mathrm{EVB}$ in compensated cirrhotic patients with initial small EV and no RCS, but may also serve as a screening tool for lowrisk patients of $\mathrm{EVB}$ and mortality who might not benefit from taking NSBB, as high NPV could correctly identifying a good prognosis patient (31). That is to say, these patients might not need prophylactic NSBB when FI is under a certain cut-off value. Moreover, these patients could continue to be monitored by regular monitoring modalities other than by endoscope within 2-year interval (9).

Esophagogastroduodenoscopy (EGD) is a common and safe procedure nowadays and can directly observe the severity of esophageal varices. However it is also expensive, mildly invasive, carries a certain degree of risk, and may be accompanied by discomfort, hence some patients are unwilling to stick to the regular monitoring schedule by endoscopy recommended by Baveno VI (10). Accordingly, many non-invasive markers were investigated for $\mathrm{EV}$ prediction power as an alternative to EGD. Deng et al. conducted a systemic review that showed APRI, AAR, FIB4, Lok, and Forns scores had low to moderate accuracy in predicting EV formation, whereas the FI was not evaluated due to a lack of reports mentioning it. This is in spite of the fact that all elements in the formula play an important role in determining liver cirrhosis severity (32). The FI is a simple and reliable tool constructed using platelet count and serum albumin for predicting fibrosis in hepatitis C (33) and B patients (34). Platelet count is a noninvasive parameter with high accuracy for predicting EVs, according to one study (35). Albumin may be useful as a first-line tool for identification of adults and pediatric patients at risk of variceal onset, and hence may reduce the number of unnecessary EGDs (36,37). In this study, FI is proposed to display acceptable performance in predicting EV bleeding within 1 year and 2 years in patients with compensated cirrhosis, initial small varices and no RCS who are not on beta-blocker and not underwent band ligation prophylaxis.
The severity of portal hypertension correlates well with HVPG $(38,39)$. According to guidelines, portal hypertension is defined as increased HVPG above $5 \mathrm{mmHg}$, and CSPH as above $10 \mathrm{mmHg}$, whereas HVPG above $12 \mathrm{mmHg}$ carries increased bleeding risk (40). Furthermore, CSPH usually develops prior to the occurrence of small EV. In turn, almost every patient with EV has already developed CSPH (41). Theoretically, we should treat EV with repeated measurement of HVPGs therapy response (42). In practice, however, HVPG is not routinely checked due to invasiveness, cost, expertise requirement, and lack of wide availability (43). Therefore, noninvasive and reproducible techniques capable of substituting HVPG would be very useful in clinical practice. HVPG is directly proportional to the severity of hepatic fibrosis (44) and many studies have demonstrated the effectiveness of non-invasive methods for predicting liver fibrosis $(33,45,46)$. Ohta et al. found that the FI could reflect histological liver fibrosis in hepatitis C (33). Koda et al. reported that Fibroindex could predict significant fibrosis in hepatitis C patients (47). Simona Bota et al. revealed that the PLF score, which includes the King's score, Forns score, and APRI, were more effective than transient elastography (TE) in predicting fibrosis in chronic hepatitis C (48). Vallet-Pichard et al. noted that FIB-4 could predict fibrosis in HCV infection (49). A systemic review and meta-analysis reported that APRI, AAR, FIB4, Lok, and Forns scores had low to moderate diagnostic accuracy in predicting the presence of varices in liver cirrhosis (32). Moreover, Kraja et al. found that FIB-4 is the only strong predictor for EV formation (17) and Bhattarai et al. demonstrated that size of spleen diameter and portal vein could correlate with severity of $\mathrm{EV}(50)$.

In recent years, elastography-based liver stiffness measurement (LSM) has been a popular tool to evaluate hepatic fibrosis, which is also used to predict $\mathrm{EV}$ formation and varices requiring treatment. But recent studies have shown that using LSM alone could produce highly variable results, thus its combination use with another non-invasive marker is suggested (51). Although in the 2015 Baveno VI consensus, it recommended that screening endoscopy for esophageal varices can be omitted in compensated liver cirrhotic patients with LSM values $<20 \mathrm{kPa}$ and platelet count (PLT) $>150 \mathrm{G} / \mathrm{L}, \mathrm{LSM}$ is resource-limited and may not be available in some hospitals or clinics. Therefore, we try to use these verified non-invasive markers to predict high and low-risk of EV bleeding in compensated cirrhotic patients with small $\mathrm{EV}$ and no RCS. The assumption is that these patients may benefit from more aggressive monitoring 
and treatment. In the last, we demonstrate that for patients with low-risk of EV bleeding signifying clinically nonsignificant portal hypertension, NSBB might not be indicated.

Take a step further, if patients in group 3 and 4 listed in Figure 3 could spare the use of NSBB, the medical costs in the CGMH system would be reduced by $\$ 14,678$ per year [(3,798 patients divided by 17 years $) \times($ propranolol $10 \mathrm{mg}$ average price is 0.06 US dollars/pill in Taiwan) $\times$ (average 3 times/day) $\times 365$ days]. Assuming that the medical costs in the CGMH system is about one-tenth of Taiwan's total national health insurance, the spared medical costs in Taiwan would be estimated \$146,780 per year. Assuming this scenario occurs in the U.S., the medical costs savings would be estimated at least $\$ 3,495,183$ per year $\{[633,323$ adults with cirrhosis/year (52)] $\times$ (at least $1.4 \%$ compensated cirrhosis with initial small $\mathrm{EV}$ and no RCS/total cirrhosis) $\times$ (propranolol $10 \mathrm{mg}$ average price is $\$ 0.36 /$ pill in U.S.) $\times(3$ times/day $) \times 365$ days $\}$. Not to mention these lowrisk patients could possibly benefit from reduced EVB and mortality.

There are limitations in this study. First, it is a retrospective cohort study. Although we enrolled a large number of patients to decrease bias, further randomized control studies are still needed to verify the benefits of FI in predicting EVB and mortality for compensated cirrhotic patients with small EV and no RCS. Second, the noninvasive markers we considered have been shown to predict liver fibrosis or EV size, but we may still overlook some other important markers. For example, TE, its data could not be retrieved in our database. Third, some other factors not mentioned in the study may also be associated with EVB, such as collateral vessel, shunting, and medications (statin, nitrate, etc.). However, the large sample size may minimize this bias statistically. Fourth, when comparing the non-NSBB group and the NSBB group for EV bleeding analysis, sex, age, CTP, MELD, FI scores, total bilirubin, albumin, platelet count, creatinine, INR, PALBI, APRI, Log score, King's score and Fib-4 index were matched. But the limitation is that the Hb, WBC, r-GT, GPR, GAR, and AST/ALT ratio did not match. There is a need for further prospective studies that match all these scores in order to compare between the two groups. Fifth, the NSBB chosen in the study were limited to propranolol (inderal) or carvedilol. Because this is a retrospective study analyzing data from CGRD, confirming the aim of NSBB prescription is used for prophylaxis of esophageal varix rupture, not for hypertension, tachycardia, heart failure is difficult. However, the 2014 statement from the "American Society of Hypertension and the International Society of Hypertension" recommend that beta-blockers not be used as first-line therapy for hypertension, particularly in patients over age 60 years. The reduction in cardiac output in patients with cirrhosis receiving propranolol might pose a detrimental effect to the heart especially during stress such as infection (53). Additionally, cirrhotic patients usually had peripheral vasodilatation resulted in hypotension (54). Therefore, we speculate that the NSBB used in cirrhosis were mostly used for primary prevention or secondary prevention of variceal hemorrhage.

In conclusion, we demonstrate that in compensated cirrhotic patients with initial small esophageal varices, no RCS, and not taking NSBB and not receiving band ligation prophylaxis therapy, FI shows a high NPV and moderate AUROC in predicting subsequent EV bleeding within 1 and 2 years. In addition, the 1-year and 2-year mortality rates for patients with FI score less than these cut-off values were also found to be low (high NPV) and even lower in patients without EV bleeding. Further sex, age and FI score matched study for EV bleeding analysis revealed that patients not taking NSBB had lower EV bleeding risks. To strengthen our assumption, we further divided our entire major group who did not take NSBB and the entire minor groups who took NSBB during follow-ups before primary endpoint into four subgroups by the FI cut-off values. The result showed that the incidence of EVB and mortality were significantly the lowest in patients with FI lower than the cut-off values and not taking NSBB. The Kaplan-Meier curve also supported that in CCC patients with initial small EV and no RCS, low FI and non-NSBB use had the best survival outcome. However, although sex, age, CTP, MELD, FI scores, total bilirubin, albumin, platelet count, creatinine, INR, PALBI, APRI, Log score, King's score and Fib-4 index were matched between the non-NSBB group and the NSBB group, the limitation is that the $\mathrm{Hb}$, WBC, r-GT, GPR, GAR, and AST/ALT ratio did not match. There is a need for further prospective studies that match all these scores in order to compare between the two groups more accurately. In summary, the FI might help patients with compensated cirrhosis, initial small EV and no RCS reducing the need of NSBB use by selecting patients with clinically non-significant portal hypertension, hence decreasing possible side effects and medical costs. However, further randomized control trial is warranted to validate this 
screening tool.

\section{Acknowledgments}

The authors are grateful to Professor Ron-Nan Chien, Professor Sen-Yung Hiseh, doctors who took care of the patients, and support from the Center for Big Data Analytics and Statistics at Chang Gung Memorial Hospital, Linkou.

Funding: This study was supported by the Chang Gung Medical Research Project: CORPG3J0071; CMRPG3E2202.

\section{Footnote}

Reporting Checklist: The authors have completed the STROBE reporting checklist. Available at http://dx.doi. org/10.21037/atm-20-2444

Data Sharing Statement: Available at http://dx.doi. org/10.21037/atm-20-2444

Peer Review File: Available at http://dx.doi.org/10.21037/ atm-20-2444

Conflicts of Interest: All authors have completed the ICMJE uniform disclosure form (available at http://dx.doi. org/10.21037/atm-20-2444). The authors have no conflicts of interest to declare.

Ethical Statement: The authors are accountable for all aspects of the work in ensuring that questions related to the accuracy or integrity of any part of the work are appropriately investigated and resolved. The study was conducted in accordance with the Declaration of Helsinki (as revised in 2013). The study was reviewed and approved by the Institutional Review Board (IRB)/ethical committees of Chang Gung Memorial Hospital (IRB number: 201802006B0). Individual consent for this retrospective analysis was waived.

Open Access Statement: This is an Open Access article distributed in accordance with the Creative Commons Attribution-NonCommercial-NoDerivs 4.0 International License (CC BY-NC-ND 4.0), which permits the noncommercial replication and distribution of the article with the strict proviso that no changes or edits are made and the original work is properly cited (including links to both the formal publication through the relevant DOI and the license). See: https://creativecommons.org/licenses/by-nc-nd/4.0/.

\section{References}

1. Sharma P, Sarin SK. Improved survival with the patients with variceal bleed. Int J Hepatol 2011;2011:356919.

2. D'Amico G, Garcia-Tsao G, Pagliaro L. Natural history and prognostic indicators of survival in cirrhosis: a systematic review of 118 studies. J Hepatol 2006;44:217-31.

3. Thomopoulos K, Theocharis G, Mimidis K, et al. Improved survival of patients presenting with acute variceal bleeding. Prognostic indicators of short- and longterm mortality. Dig Liver Dis 2006;38:899-904.

4. Zipprich A, Garcia-Tsao G, Rogowski S, et al. Prognostic indicators of survival in patients with compensated and decompensated cirrhosis. Liver Int 2012;32:1407-14.

5. Tripathi D, Stanley AJ, Hayes PC, et al. U.K. guidelines on the management of variceal haemorrhage in cirrhotic patients. Gut 2015;64:1680-704.

6. Robertson M, Hayes P. Primary prophylaxis of variceal bleeding. Hepatol Int 2018;12:1-5.

7. North Italian Endoscopic Club for the Study and Treatment of Esophageal Varices. Prediction of the first variceal hemorrhage in patients with cirrhosis of the liver and esophageal varices. A prospective multicenter study. $\mathrm{N}$ Engl J Med 1988;319:983-9.

8. de Franchis R, Primignani M. Natural history of portal hypertension in patients with cirrhosis. Clin Liver Dis 2001;5:645-63.

9. Garcia-Tsao G, Abraldes JG, Berzigotti A, et al. Portal hypertensive bleeding in cirrhosis: Risk stratification, diagnosis, and management: 2016 practice guidance by the American Association for the study of liver diseases. Hepatology 2017;65:310-35.

10. de Franchis R, Baveno VIF. Expanding consensus in portal hypertension: Report of the Baveno VI Consensus Workshop: Stratifying risk and individualizing care for portal hypertension. J Hepatol 2015;63:743-52.

11. Calés P, Oberti F, Payen JL, et al. Lack of effect of propranolol in the prevention of large oesophageal varices in patients with cirrhosis: a randomized trial. FrenchSpeaking Club for the Study of Portal Hypertension. Eur J Gastroenterol Hepatol 1999;11:741-5.

12. Merkel C, Marin R, Angeli P, et al. A placebo-controlled clinical trial of nadolol in the prophylaxis of growth of small esophageal varices in cirrhosis. Gastroenterology 2004;127:476-84. 
13. Sarin SK, Mishra SR, Sharma P, et al. Early primary prophylaxis with beta-blockers does not prevent the growth of small esophageal varices in cirrhosis: a randomized controlled trial. Hepatol Int 2013;7:248-56.

14. Abraldes JG, Sarlieve P, Tandon P. Measurement of portal pressure. Clin Liver Dis 2014;18:779-92.

15. Thalheimer U, Mela M, Patch D, et al. Monitoring target reduction in hepatic venous pressure gradient during pharmacological therapy of portal hypertension: a close look at the evidence. Gut 2004;53:143-8.

16. Hicken BL, Sharara AI, Abrams GA, et al. Hepatic venous pressure gradient measurements to assess response to primary prophylaxis in patients with cirrhosis: a decision analytical study. Aliment Pharmacol Ther 2003;17:145-53.

17. Kraja B, Mone I, Akshija I, et al. Predictors of esophageal varices and first variceal bleeding in liver cirrhosis patients. World J Gastroenterol 2017;23:4806-14.

18. Chen PH, Hsieh WY, Su CW, et al. Combination of albumin-bilirubin grade and platelets to predict a compensated patient with hepatocellular carcinoma who does not require endoscopic screening for esophageal varices. Gastrointest Endosc 2018;88:230-9.e2.

19. Tsai MS, Lin MH, Lee CP, et al. Chang Gung Research Database: A multi-institutional database consisting of original medical records. Biomed J 2017;40:263-9.

20. Shao SC, Chan YY, Kao Yang YH, et al. The Chang Gung Research Database-A multi-institutional electronic medical records database for real-world epidemiological studies in Taiwan. Pharmacoepidemiol Drug Saf 2019;28:593-600.

21. Ponziani FR, Annicchiarico EB, Siciliano M, et al. Treatment of hepatitis $\mathrm{C}$ in compensated cirrhotic patients is equally effective before and after liver transplantation. World J Gastroenterol 2013;19:3255-62.

22. Miyaaki H, Ichikawa T, Taura N, et al. Endoscopic management of esophagogastric varices in Japan. Ann Transl Med 2014;2:42.

23. Kleber G, Sauerbruch T, Ansari H, et al. Prediction of variceal hemorrhage in cirrhosis: a prospective follow-up study. Gastroenterology 1991;100:1332-7.

24. Hanley JA, McNeil BJ. A method of comparing the areas under receiver operating characteristic curves derived from the same cases. Radiology 1983;148:839-43.

25. Garcia-Tsao G, Sanyal AJ, Grace ND, et al. Prevention and management of gastroesophageal varices and variceal hemorrhage in cirrhosis. Hepatology 2007;46:922-38.

26. Mandorfer M, Peck-Radosavljevic M, Reiberger T. Prevention of progression from small to large varices: are we there yet? An updated meta-analysis. Gut
2017;66:1347-9.

27. Møller S, Bendtsen F. The pathophysiology of arterial vasodilatation and hyperdynamic circulation in cirrhosis. Liver Int 2018;38:570-80.

28. Tergast TL, Kimmann M, Laser H, et al. Systemic arterial blood pressure determines the therapeutic window of non-selective beta blockers in decompensated cirrhosis. Aliment Pharmacol Ther 2019;50:696-706.

29. Tapper EB, Parikh ND, Sengupta N, et al. A risk score to predict the development of hepatic encephalopathy in a population-based cohort of patients with cirrhosis. Hepatology 2018;68:1498-507.

30. Villanueva C, Albillos A, Genesca J, et al. beta blockers to prevent decompensation of cirrhosis in patients with clinically significant portal hypertension (PREDESCI): a randomised, double-blind, placebo-controlled, multicentre trial. Lancet 2019;393:1597-608.

31. Teschendorff AE, Caldas C. A robust classifier of high predictive value to identify good prognosis patients in ERnegative breast cancer. Breast Cancer Res 2008;10:R73.

32. Deng H, Qi X, Guo XJM. Diagnostic accuracy of APRI, AAR, FIB-4, FI, King, Lok, Forns, and FibroIndex scores in predicting the presence of esophageal varices in liver cirrhosis: a systematic review and meta-analysis. Medicine (Baltimore) 2015;94:e1795.

33. Ohta T, Sakaguchi K, Fujiwara A, et al. Simple surrogate index of the fibrosis stage in chronic hepatitis $\mathrm{C}$ patients using platelet count and serum albumin level. Acta Med Okayama 2006;60:77.

34. Coskun BD, Altinkaya E, Sevinc E, et al. The diagnostic value of a globulin/platelet model for evaluating liver fibrosis in chronic hepatitis B patients. Rev Esp Enferm Dig 2015;107:740-4.

35. Abd-Elsalam S, Habba E, Elkhalawany W, et al. Correlation of platelets count with endoscopic findings in a cohort of Egyptian patients with liver cirrhosis. Medicine (Baltimore) 2016;95:e3853.

36. Adami MR, Ferreira CT, Kieling CO, et al. Noninvasive methods for prediction of esophageal varices in pediatric patients with portal hypertension. World J Gastroenterol 2013;19:2053-9.

37. Gana JC, Turner D, Roberts EA, et al. Derivation of a clinical prediction rule for the noninvasive diagnosis of varices in children. J Pediatr Gastroenterol Nutr 2010;50:188-93.

38. Groszmann RJ, Wongcharatrawee S. The hepatic venous pressure gradient: anything worth doing should be done right. Hepatology 2004;39:280-2. 


\section{Page 18 of 18}

39. Thalheimer U, Leandro G, Samonakis DN, et al. Assessment of the agreement between wedge hepatic vein pressure and portal vein pressure in cirrhotic patients. Dig Liver Dis 2005;37:601-8.

40. Suk KT. Hepatic venous pressure gradient: clinical use in chronic liver disease. Clin Mol Hepatol 2014;20:6-14.

41. Bosch J, Groszmann RJ, Shah VH. Evolution in the understanding of the pathophysiological basis of portal hypertension: how changes in paradigm are leading to successful new treatments. J Hepatol 2015;62:S121-S130.

42. Reiberger T, Bucsics T, Paternostro R, et al. Small Esophageal Varices in Patients with Cirrhosis-Should We Treat Them? Curr Hepatol Rep 2018;17:301-15.

43. Ravaioli F, Montagnani M, Lisotti A, et al. Noninvasive Assessment of Portal Hypertension in Advanced Chronic Liver Disease: An Update. Gastroenterol Res Pract 2018;2018:4202091.

44. Berzigotti A, Seijo S, Reverter E, et al. Assessing portal hypertension in liver diseases. Expert Rev Gastroenterol Hepatol 2013;7:141-55.

45. Lok AS, Ghany MG, Goodman ZD, et al. Predicting cirrhosis in patients with hepatitis $\mathrm{C}$ based on standard laboratory tests: results of the HALT-C cohort. Hepatology 2005;42:282-92.

46. Poynard T, Morra R, Ingiliz P, et al. Assessment of liver fibrosis: noninvasive means. Saudi J Gastroenterol 2008; $14: 163$.

Cite this article as: Wang SF, Huang YT, Huang $\mathrm{CH}$, Chang SH, Lin CY. Fibrosis index predicts variceal bleeding and reduces need for nonselective beta-blocker in compensated cirrhosis with initial small esophageal varices without red-color sign. Ann Transl Med 2020;8(19):1223. doi: 10.21037/atm-202444
Wang et al. Low FI decrease need for NSBB use in cirrhosis

47. Koda M, Matunaga Y, Kawakami M, et al. FibroIndex, a practical index for predicting significant fibrosis in patients with chronic hepatitis C. Hepatology 2007;45:297-306.

48. Bota S, Sirli R, Sporea I, et al. A new scoring system for prediction of fibrosis in chronic hepatitis C. Hepat Mon 2011;11:548-55.

49. Vallet-Pichard A, Mallet V, Nalpas B, et al. FIB-4: an inexpensive and accurate marker of fibrosis in $\mathrm{HCV}$ infection. comparison with liver biopsy and fibrotest. Hepatology 2007;46:32-6.

50. Bhattarai S, Dewan KR, Shrestha G, et al. Non-Invasive Predictors of Gastro-Oesophageal Varices. JNMA J Nepal Med Assoc 2017;56:298-303.

51. Paternostro R, Reiberger T, Bucsics T. Elastographybased screening for esophageal varices in patients with advanced chronic liver disease. World J Gastroenterol 2019;25:308-29.

52. Scaglione S, Kliethermes S, Cao G, et al. The Epidemiology of Cirrhosis in the United States: A Population-based Study. J Clin Gastroenterol 2015;49:690-6.

53. Wong F, Salerno F. Beta-blockers in cirrhosis: friend and foe? Hepatology 2010;52:811-3.

54. Newby DE, Hayes PJQ. Hyperdynamic circulation in liver cirrhosis: not peripheral vasodilatation but 'splanchnic steal'. QJM 2002;95:827-30. 
Supplementary

Table S1 The formula for non-invasive markers were as follows

\begin{tabular}{|c|c|}
\hline MELD score & $9.57 \times$ loge $[$ creatinine $(\mathrm{mg} / \mathrm{dL})]+3.78 \times$ loge[bilirubin $(\mathrm{mg} / \mathrm{dL})]+11.2 \times$ loge $(\mathrm{INR})+6.43$ \\
\hline rGT platelet ration (GPR) & [(rGT/its ULN: male: 71 ; female: 42$) /$ platelet $\left.\left(10^{9} / L\right)\right] \times 100$ \\
\hline GAR & rGT (IU/L)/10x albumin (g/dL) \\
\hline AST/ALT ratio & AST/ALT \\
\hline King score & Age $($ years $) \times$ AST $(\mathrm{U} / \mathrm{L}) \times$ INR/Platelet $\left(10^{9} / \mathrm{L}\right)$ \\
\hline Forns score & $\begin{array}{l}\left.7.811-3.131 \times \text { In [platelets }\left(10^{\circ} / \mathrm{l}\right)\right]+0.781 \mathrm{In}[\mathrm{rGT}(\mathrm{U} / \mathrm{L})]+3.467 \times \ln \text { [age (years)] }-0.014 \text { [cholesterol } \\
(\mathrm{mg} / \mathrm{dL})]\end{array}$ \\
\hline PALBI score & $\begin{array}{l}(2.02 \times \text { Log10bilirubin })+\left[-0.37 \times(\text { Log10bilirubin })^{2}\right]+(-0.04 \times \text { albumin })+[-3.48 \times \text { Log } 10 \text { platelets }) \\
+\left[1.01 \times(\text { Log10 platelets })^{2}\right]\end{array}$ \\
\hline PALBI grade & PALBI grade 1 (score $\leq-2.53$ ) \\
\hline PLF score & $0.956+0.084 \times \mathrm{TE}-0.004 \times$ King score $+0.124 \times$ Forns score $+0.202 \times$ APRI score \\
\hline ALBI score & $\left(\log _{10}\right.$ bilirubin $\left.\times 0.66\right)+($ albumin $\times-0.085)$, bilirubin is in $\mu \mathrm{mol} / \mathrm{L}$ and albumin in $\mathrm{g} / \mathrm{L}$ \\
\hline \multirow[t]{3}{*}{ ALBI grade } & ALBI grade $1(\leq-2.60)$ \\
\hline & ALBI grade $2(>-2.60$ to $\leq-1.39)$ \\
\hline & ALBI grade $3(>-1.39)$ \\
\hline GUCl & $($ AST/34) $\times$ INR $\times 100 /$ platelet \\
\hline Lok score & $-5.56-0.0089 \times$ number of platelets $\left(10^{3} / \mathrm{mm}^{3}\right)+1.26 \times($ AST/ALT $)+5.27 \times$ INR \\
\hline
\end{tabular}


Table S2 Statistical differences between EV bleeding and non-EV bleeding within 2 years

\begin{tabular}{|c|c|c|c|}
\hline Variables & EV bleeding, $n=710$ (10.44\%) & Non-EV bleeding, $n=6,093$ (89.56\%) & $\mathrm{P}$ \\
\hline Male, n (\%) & $523(73.66)$ & 4,307 (70.69) & 0.0984 \\
\hline Age (years, mean $\pm S D$ ) & $57.17 \pm 13.75$ & $59.20 \pm 12.40$ & $<0.001$ \\
\hline $\begin{array}{l}\text { Follow-up duration (months, mean } \pm \text { SD) to } \\
\text { bleeding }\end{array}$ & $6.30(7.32)$ & $23.23(3.76)$ & $<0.001$ \\
\hline Etiology, n (\%) & & & $<0.001$ \\
\hline HBV & $259(36.48)$ & $2,822(46.32)$ & \\
\hline $\mathrm{HCV}$ & $140(19.72)$ & $1,193(19.58)$ & \\
\hline Alcohol & 105 (14.79) & $545(8.94)$ & \\
\hline Others & $206(29.01)$ & $1,533(25.16)$ & \\
\hline \multicolumn{4}{|l|}{ Baseline laboratory value [mean (SD)] } \\
\hline AST (U/L) & $95.02(131.6)$ & $89.86(176.20)$ & 0.3371 \\
\hline ALT (U/L) & $54.49(62.08)$ & $64.60(97.92)$ & 0.015 \\
\hline $\mathrm{Cr}(\mathrm{mg} / \mathrm{dL})$ & $1.39(1.53)$ & $1.34(1.57)$ & 0.1178 \\
\hline $\mathrm{Na}(\mathrm{mEq} / \mathrm{L})$ & $136.0(11.64)$ & $137.3(8.50)$ & $<0.001$ \\
\hline $\mathrm{K}(\mathrm{mEq} / \mathrm{L})$ & $4.06(1.85)$ & $4.03(1.10)$ & 0.1554 \\
\hline Bilirubin-total (mg/dL) & $3.05(4.77)$ & $2.58(4.38)$ & $<0.001$ \\
\hline Albumin (g/dL) & $3.04(0.84)$ & $3.39(0.83)$ & $<0.001$ \\
\hline PT-INR & $1.35(0.34)$ & $1.30(0.52)$ & 0.0032 \\
\hline $\mathrm{Hb}(\mathrm{g} / \mathrm{dL})$ & $10.27(2.52)$ & $11.59(2.73)$ & $<0.001$ \\
\hline WBC $(\times 1,000 / \mu L)$ & $7.14(4.41)$ & $6.52(3.95)$ & $<0.001$ \\
\hline Platelet $(\times 1,000 / \mu \mathrm{L})$ & $111.30(95.34)$ & $121.80(75.64)$ & 0.5088 \\
\hline r-GT & $208.40(266.4)$ & $147.70(238.1)$ & 0.0079 \\
\hline Cholesterol & $154.60(44.91)$ & $162.90(47.48)$ & $<0.001$ \\
\hline Antivirals for HBV \% (n/N) & $35.9 \%(93 / 259)$ & $40.9 \%(1,175 / 2,822)$ & \\
\hline \multicolumn{4}{|l|}{ Prognostic systems [mean (SD)] } \\
\hline CTP score & $6.84(1.56)$ & $6.45(1.53)$ & $<0.001$ \\
\hline MELD score & $14.08(5.90)$ & $13.09(6.17)$ & $<0.001$ \\
\hline MELD-Na score & $16(8.04)$ & $14.83(8.37)$ & $<0.001$ \\
\hline PALBI score & $-2.52(0.69)$ & $-2.66(0.69)$ & $<0.001$ \\
\hline $\begin{array}{l}\text { Gamma-glutamyl transpeptidase-to-platelet } \\
\text { ratio (GPR) }\end{array}$ & $4.04(7.28)$ & $2.46(4.51)$ & $<0.001$ \\
\hline $\begin{array}{l}\text { Gamma-glutamyl transpeptidase-to-albumin } \\
\text { ratio (GAR) }\end{array}$ & $7.81(13.82)$ & $5.56(41.39)$ & 0.4374 \\
\hline AST/ALT & $2.14(1.82)$ & $1.66(1.34)$ & $<0.001$ \\
\hline AST to platelet ratio index (APRI) & $4.17(8.20)$ & $3.60(18.64)$ & 0.4724 \\
\hline Platelet count to spleen diameter (PC/SD) & $18.87(13.59)$ & $23.38(17.26)$ & 0.0032 \\
\hline Fibrosis-4-index (FIB-4) & $11.44(24.11)$ & $9.12(72.96)$ & 0.4764 \\
\hline Fibrosis index (FI) & $3.85(1.32)$ & $3.41(1.18)$ & $<0.001$ \\
\hline King's score & $115.20(288.6)$ & $120.1(102.6)$ & 0.9605 \\
\hline Lok score & $3.28(3.53)$ & $2.41(3.60)$ & $<0.001$ \\
\hline Lok index & $0.85(0.19)$ & $0.78(0.22)$ & $<0.001$ \\
\hline Portal vein size & $1.15(0.25)$ & $1.11(0.24)$ & 0.0034 \\
\hline Forns index & $11.27(2.07)$ & $10.72(1.97)$ & 0.0056 \\
\hline
\end{tabular}

EV, esophageal variceal; AST, aspartate aminotransferase; ALT, alanine aminotransferase. 
Table S3 Univariable and multivariable Cox regression analysis for prediction of EV bleeding within 2 years

\begin{tabular}{|c|c|c|c|c|}
\hline Variables & \multicolumn{2}{|c|}{ Univariable } & \multicolumn{2}{|c|}{ Multivariable (stepwise) } \\
\hline Age & $0.998(0.982-0.994)$ & $<0.001$ & & \\
\hline \multicolumn{5}{|l|}{ Sex } \\
\hline Male & 1 & & & \\
\hline \multicolumn{5}{|l|}{ Etiology } \\
\hline HBV & $0.71(0.58-0.87)$ & 0.001 & & \\
\hline $\mathrm{HCV}$ & $0.88(0.71-1.09)$ & 0.225 & & \\
\hline Alcohol & $1.4(1.106-1.77)$ & 0.005 & & \\
\hline CTP score & $1.170(1.112-1.231)$ & $<0.001$ & & \\
\hline MELD score & $1.027(1.014-1.040)$ & $<0.001$ & & \\
\hline MELD-Na score & 1.017 (1.008-1.027) & 0.0002 & & \\
\hline PALBI score & $1.341(1.199-1.500)$ & $<0.001$ & & \\
\hline Spleen diameter & $1.146(1.067-1.232)$ & 0.0002 & & \\
\hline GUCl & $1.001(0.999-1.002)$ & 0.5491 & & \\
\hline $\begin{array}{l}\text { Gamma-glutamyl transpeptidase- } \\
\text { to-platelet ratio (GPR) }\end{array}$ & $1.031(1.020-1.042)$ & $<0.001$ & $1.039(1.018-1.060)$ & 0.0002 \\
\hline Fibrosis-4-index (FIB-4) & 1.001 (1.000-1.002) & 0.0019 & & \\
\hline Fibrosis index (FI) & $1.378(1.282-1.482)$ & $<0.001$ & $1.373(1.156-1.630)$ & 0.0003 \\
\hline King's score & $1.000(1.000-1.000)$ & 0.6824 & & \\
\hline Lok score & 1.037 (1.024-1.051) & $<0.001$ & & \\
\hline Lok index & $6.196(3.818-10.5)$ & $<0.001$ & & \\
\hline Portal vein size & $1.955(1.177-3.246)$ & 0.0096 & & \\
\hline Forns index & $1.142(1.084-1.204)$ & $<0.001$ & & \\
\hline
\end{tabular}

The C-index for prediction of 2-year EV bleeding in this multivariable logistic regression model was 0.63 with $95 \% \mathrm{Cl}(0.59-0.65)$. The $\mathrm{FI}$ with a cut-off value of 3.31 showed a negative predictive value (NPV) of 93.3\% for predicting subsequent EV bleeding and NPV of $96.02 \%$ for predicting mortalities within 1 year. 
Table S4 The sensitivity, specificity, and positive and negative predictive values for fibrosis index (FI) best cut-off values in predicting EVB within 1 and 2 years respectively

\begin{tabular}{|c|c|c|c|c|}
\hline $\begin{array}{l}\text { FI cut-off values for } \\
\text { predicting EVB }\end{array}$ & Sensitivity & Specificity & PPV & NPV \\
\hline 3.95 (within 1 year) & $51.2 \%$ & $66.3 \%$ & $11.0 \%$ & $94.3 \%$ \\
\hline
\end{tabular}

Table S5 The sensitivity, specificity, and positive and negative predictive values for fibrosis index (FI) best cut-off values in predicting mortalities within 1 and 2 years respectively

\begin{tabular}{|c|c|c|c|c|}
\hline $\begin{array}{l}\text { FI cut-off values for } \\
\text { predicting mortality }\end{array}$ & Sensitivity & Specificity & PPV & NPV \\
\hline 3.95 (within 1 year) & $49.30 \%$ & $65.50 \%$ & $5.37 \%$ & $97.02 \%$ \\
\hline 3.31 (within 2 years) & $66.89 \%$ & $43.80 \%$ & $6.13 \%$ & $96.02 \%$ \\
\hline
\end{tabular}

